Article

\title{
Study of Carbon Black Types in SBR Rubber: Mechanical and Vibration Damping Properties
}

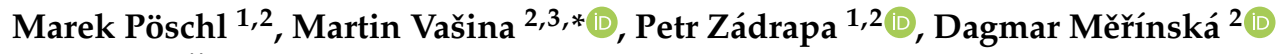 \\ and Milan Žaludek ${ }^{2}$ \\ 1 Centre of Polymer Systems, University Institute, Tomas Bata University in Zlin, Tř́ida Tomáše \\ Bati 5678, 76001 Zlin, Czech Republic; poschl@utb.cz (M.P.); zadrapa@utb.cz (P.Z.) \\ 2 Faculty of Technology, Tomas Bata University in Zlin, Vavrečkova 275, 76001 Zlin, Czech Republic; \\ merinska@utb.cz (D.M.); zaludek@utb.cz (M.Ž.) \\ 3 Faculty of Mechanical Engineering, VŠB-Technical University of Ostrava, 17. Listopadu 15/2172, \\ 70833 Ostrava-Poruba, Czech Republic \\ * Correspondence: vasina@utb.cz
}

Received: 20 April 2020; Accepted: 19 May 2020; Published: 22 May 2020

check for updates

\begin{abstract}
Styrene-butadiene rubber mixtures with four types of carbon black were studied in this paper. The mechanical properties, including the ability to damp mechanical vibration, were investigated, along with dynamical mechanical analysis (DMA). It has been found that carbon black types N 110 and N 330, having the largest specific surface area and the smallest particle diameter, provide a good stiffening effect. These particles have significant interactions between the rubber, resulting in good reinforcement. On the other hand, the carbon black N 990 type has a lower reinforcing effect and improved vibration damping properties at higher excitation frequencies due to higher dissipation of mechanical energy into heat under dynamic loading. The effect of the number of loading cycles on vibration damping properties of the rubber composites was also investigated in this study. It can be concluded that the abovementioned properties of the investigated rubber composites correspond to physical-mechanical properties of the applied carbon black types.
\end{abstract}

Keywords: vulcanized rubber; rubber compounds; carbon black; vibration damping; viscoelasticity

\section{Introduction}

Mechanical vibration, which is caused by oscillation of a mechanical or structural system about an equilibrium position, is an undesirable phenomenon in many cases (e.g., manufacturing processes, means of transport, and in home appliances). Furthermore, the mechanical vibration can contribute to excessive noise and have a negative effect on labor protection, manufacturing quality, and productivity. For these reasons, it is necessary to eliminate the mechanical vibration through appropriate measures, e.g., by application of suitable vibration damping materials [1-3].

Polymers have become more frequently used in a variety of applications in order to diminish vibration [2] in cars, ships, and other products where machinery creates vibration [4] or there are natural causes of vibration, which should be lowered from the environment in question. Anechoic chambers exist that allow for accurate observation of sound energy. Given or created energy is treated by dissipation or absorption by a variety of mechanisms [5].

In an engineering system, a structure should stay stable and undamaged despite internal and external vibrations. The stability of a system depends on its damping ability, which can be influenced by the composition of rubber mixtures [6,7]. Damping is defined as the energy dissipation of a vibration system and it can be presented by various parameters, one of which is the loss factor. The loss factor can 
be determined by several different methods, which are grouped into time, deformation, temperature, and frequency sweep tests $[7,8]$.

All rubber mixture's properties are mainly influenced by its composition. The rubber type is only the base of the compound. In order to achieve the best properties in the finished rubber product, it is necessary to add some additives to the rubber to significantly change the properties of the product and improve its resistance to various undesirable effects. The additive component is given in units of $\mathrm{phr}$, which is the weight per 100 parts by weight of rubber [9]. The most important rubber components include the vulcanizing agents, accelerators, activators, retarders (inhibitors), antidegradants, fillers, plasticizers, and special additives [10-13].

Two main types of additives are involved in the material's ability to dampen mechanical vibration. Firstly, the oil or plasticizer significantly contributes to determining the damping characteristics. The oil choice is usually decided by the required low temperature flexibility and by damping characteristics. Secondly, the carbon black type and its amount are significant factors that influence the damping characteristics of a rubber compound [14-16].

The aim of this study is to investigate mechanical and vibration damping properties of rubber composites containing different carbon black primary particle sizes with slightly different properties. In order to determine the influence of a carbon black structure on mechanical and vibration damping properties, the rubber mixture compositions were prepared with the same carbon black volume concentration.

\section{Materials and Methods}

\subsection{Materials}

Styrene butadiene rubber (SBR) SBR 1500 (Synthos Kralupy a.s., Kralupy nad Vltavou, Czech Republic), was used as the base for rubber compounds. Carbon black grades N 110, N 330, N 550, and N 990 from CS Cabot, s.r.o. (Valašské Meziř́čí, Czech Republic), were used as fillers. The additives, including $\mathrm{ZnO}$ from SlovZink a.s. (Košeca, Slovakia), stearic acid from Setuza a.s. (Ústí nad Labem, Czech Republic), N-tert-butyl-benzothiazole sulfonamide (TBBS) from Duslo a.s. (Šal'a, Slovakia), and sulphur type Crystex OT33 from Eastman Chemical company (Kingsport, Tennessee, USA), were also compounded. The rubber recipe is given in Table 1.

Table 1. Rubber compound recipe. SBR, styrene butadiene rubber; TBBS, N-tert-butyl-benzothiazole sulfonamide.

\begin{tabular}{cc}
\hline Ingredients & Loading [phr] \\
\hline SBR & 100 \\
Carbon black & 50 \\
ZnO & 3 \\
Stearic acid & 1 \\
TBBS & 1 \\
Sulfur & 1.75 \\
\hline
\end{tabular}

Iodine adsorption (IA) and dibutyl phthalate absorption (DBPA) methods were used in order to characterize the carbon black more precisely. While the surface area could be characterized by the first method, the second one was used for secondary structure characterization. The IA of the studied carbon black types was $145,82,43$, and $10 \mathrm{~g} \times \mathrm{kg}^{-1}$ for N 110, N 330, N 550, and N 990, respectively. The secondary structure was more similar for N 110, N 330, and N 550 carbon black types $(113,102$, and $121 \mathrm{~mL} \times 100 \mathrm{~g}^{-1}$, respectively). However, the last filler type (N 990) was characterized by the lowest secondary structure, with a DBPA of $35 \mathrm{~mL} \times 100 \mathrm{~g}^{-1}$. The primary carbon black particle sizes were measured using JEM-2100 transmission electron microscope (JEOL Ltd., Tokyo, Japan) and the average diameters of the studied carbon black were about $15 \mathrm{~nm}$ for N 110, $27 \mathrm{~nm}$ for N 330, $55 \mathrm{~nm}$ for $\mathrm{N} 550$, and $280 \mathrm{~nm}$ for $\mathrm{N} 990$. The optimal filler concentration in a polymer matrix is strongly influenced 
by the stiffening effect (particle size, shape, and structure) of the filler. With decreasing particle size, the stiffening effect increases. A filler value of $50 \mathrm{phr}$ was chosen as the optimal concentration for various types of carbon black to be able to evaluate their effects on the studied properties. At the given phr concentration, most of rubber mixtures exhibits optimal physical-mechanical properties.

\subsection{Obtaining the Mixtures and Sample Preparation}

The basic rubber compounds (SBR, carbon black, $\mathrm{ZnO}$, and stearic acid) were mixed in a Banbury laboratory internal mixer (Farrel Pominy, Castellanza, Italy) (volume $0.41 \mathrm{~L}$, fill factor 0.72, chamber temperature $70{ }^{\circ} \mathrm{C}$ ) for $8 \mathrm{~min}$ at $80 \mathrm{rpm}$. Consequently, the compounds were cooled down to $80^{\circ} \mathrm{C}$ over a period of $1 \mathrm{~min}$ on a double roll mill $(150 \mathrm{~mm} \times 330 \mathrm{~mm}$, Farrel) at a rotation speed ratio of 1:1.2. Finally, the accelerator and sulphur were added and mixed for the next $6 \mathrm{~min}$.

\subsection{Methods}

\subsubsection{Curing Characterization}

Curing characteristics were measured on the Premier MDR moving die rheometer from Monsanto Company (Dayton, Ohio, USA) at a constant temperature of $160{ }^{\circ} \mathrm{C}$. Scorch $\left(t_{s 1}\right)$ and optimum cure $\left(t_{90}\right)$ times were evaluated by these measurements.

Consequently, compression molding in a hydraulic press at $20 \mathrm{MPa}$ and $160{ }^{\circ} \mathrm{C}$ was used for the test sheet preparation. The samples sheets $(150 \mathrm{~mm} \times 150 \mathrm{~mm})$ for mechanical tests measured 1 and $2 \mathrm{~mm}$ in thickness, cylinders measured 10,15, 20, and $80 \mathrm{~mm}$ in diameter for vibration tests, and cylinders measured 20 and $100 \mathrm{~mm}$ in diameter for cyclic pressure tests. The samples measuring up to $2 \mathrm{~mm}$ in thickness were molded over the given time period, which is given by the time $t_{90}$. The curing time for samples thicker than $2 \mathrm{~mm}$ was calculated as the value of time $t_{90}$ with the addition of $1 \mathrm{~min}$ per each $1 \mathrm{~mm}$ of sample thickness.

\subsubsection{Quasistatic Mechanical Properties}

Tensile tests were performed on the T10D tensile testing machine from Alpha Technology (Hudson, Ohio, USA), according to ISO 37 standard. Ten specimens (type 2, elongation speed of $500 \mathrm{~mm} / \mathrm{min}$ ) were tested in this case. The average values of the measured quantities and their standard deviations were subsequently evaluated.

Shore A hardness was measured according to ISO 7619 standard. Samples measuring $6 \mathrm{~mm}$ in thickness were tested and the parameters (median and arithmetic average) were obtained from nine measured values.

Rubber rebound resilience was measured according to ISO 4662 standard. The sample measuring $10 \mathrm{~mm}$ in thickness was examined and the average values of the resilience, including its standard deviations from 6 values, were subsequently determined. These tests were carried out at an ambient temperature of $22^{\circ} \mathrm{C}$.

\subsubsection{Dynamical Mechanical Properties}

Dynamical mechanical analysis (DMA) of the vulcanized rubber samples measuring $t=1 \mathrm{~mm}$ in thickness and $w=6 \mathrm{~mm}$ in width was realized on the Mettler Toledo DMA 1 equipment (Columbus, Ohio, USA) in tensile mode. Firstly, the temperature sweep was measured in a temperature range of $-80{ }^{\circ} \mathrm{C}$ to $+20{ }^{\circ} \mathrm{C}$, with a temperature rate of $2{ }^{\circ} \mathrm{C} / \mathrm{min}$, at a constant deformation rate of $5 \mu \mathrm{m}$ and a frequency of $20 \mathrm{~Hz}$. Secondly, the frequency sweep was studied at a constant deformation rate of $10 \mu \mathrm{m}$ and at $25^{\circ} \mathrm{C}$, with varying frequency ranging from 0 to $250 \mathrm{~Hz}$. Finally, the strain sweep was studied at a constant frequency of $20 \mathrm{~Hz}$ and at $25^{\circ} \mathrm{C}$, with varying strain ranging from 0 to $200 \mu \mathrm{m}$. Three measurements were taken for each compound.

The dynamic shear properties were measured on the Premier RPA rubber process analyzer from Alpha Technology (Hudson, Ohio, USA). Rubber compounds were firstly cured for $t_{90}$ at $160{ }^{\circ} \mathrm{C}$. 
The rubber sample was subsequently cooled down to $60{ }^{\circ} \mathrm{C}$ (cooling rate of $30{ }^{\circ} \mathrm{C} / \mathrm{min}$ ), followed by temperature stabilization for $3 \mathrm{~min}$. Finally, the sample was deformed from $0.1 \%$ to $200 \%$ at frequency $f=1 \mathrm{~Hz}$. Again, three measurements were performed for each compound.

\subsubsection{The Hysteresis Characteristics}

The hysteresis characteristics of the rubber compounds were evaluated on the ZwickRoell tensile testing machine (ZwickRoell, Ulm, Germany) in compression mode. The samples measuring $100 \mathrm{~mm}$ in diameter and $20 \mathrm{~mm}$ in thickness were tested. Cyclic deformation of $10 \%$ at $50 \mathrm{~mm} / \mathrm{min}$ was applied to each sample. The total number of 100 cycles was performed to reach a steady state of the hysteresis loop. The tests were carried out at $23{ }^{\circ} \mathrm{C}$. Cycling loading tests of vibration damping were also performed with the same machine. The rubber samples were cyclically loaded for $0 ; 100,000 ; 250,000$; 500,000 ; and 750,000 cycles at a constant force of $10 \mathrm{kN}$, excitation frequency $f=20 \mathrm{~Hz}$, and ambient temperature of $23^{\circ} \mathrm{C}$.

\subsubsection{Mechanical Vibration Damping Measurement}

In general, vibration measurement methods are divided into contacting and contactless types [17-20]. The contactless vibration measurement methods can be performed using inductive, capacitive, optical (e.g., laser triangulation and laser interference), and ultrasonic sensors. They can be applied to measure deflections of rotary components, as well as higher vibration amplitudes and excitation frequencies compared to the contacting vibration measurements, which can be performed using piezoelectric and microelectro mechanical system (MEMS) accelerometers. The accelerometers are mounted directly on the vibrating component and are being used more widely due to the rapid development of electronic technology, accompanying secondary instrument, and low-noise cables, and their high insulation resistance and small capacitance.

The vibration damping properties of the investigated rubber composites can be examined by different methods, namely using the free vibration method and by using harmonically excited vibration [21,22]. The free vibration method evaluates a material's ability to dampen mechanical vibrations based on the logarithmic decrement $\delta$ and the damping ratio $\zeta$. For harmonically excited vibration, which can be achieved under harmonic force or under the harmonic motion of a base, the vibration damping properties are characterized by the frequency dependencies of amplitude ratios (e.g., amplification factor or displacement transmissibility). The method involving harmonically excited vibration based on the response of a damped system under the harmonic motion of the base (so-called kinematic excitation), which is relatively simple, was applied in order to investigate the vibration damping properties of the studied rubber composites.

A material's ability to damp mechanical vibration can be characterized by the transfer damping function $D(\mathrm{~dB})$, which is expressed by the following equation [23]:

$$
D=20 \cdot \log \frac{v_{01}}{v_{02}}
$$

where $v_{01}$ is the velocity amplitude on the input (i.e., excitation) side of the tested sample and $v_{02}$ is the velocity amplitude on the output side of the tested sample. For harmonically excited vibration, it is also possible to express the transfer damping function as follows:

$$
D=20 \cdot \log \frac{y_{01}}{y_{02}}=20 \cdot \log \frac{a_{01}}{a_{02}}
$$

where $y_{01}\left(a_{01}\right)$ is the displacement (acceleration) amplitude on the input side of the tested sample and $y_{02}\left(a_{02}\right)$ is the displacement (acceleration) amplitude on the output side of the tested sample. There are three different types of mechanical vibration depending on the transfer damping function value, namely damped $(D>0)$, undamped $(D=0)$, and resonance $(D<0)$ vibration. 
The mechanical vibration damping testing of the tested rubber composite materials was performed using the forced oscillation method. The transfer damping function was experimentally measured using the BK 4810 mini-shaker (Brüel and Kjær, Nærum, Denmark) in combination with a BK 3560-B-030 signal pulse multi-analyzer (Brüel and Kjær, Nærum, Denmark) and a BK 2706 power amplifier (Brüel and Kjær, Nærum, Denmark) at the frequency range of 2-3200 Hz (see Figure 1). Sine waves were generated by the mini-shaker. The acceleration amplitudes on the input and output sides of the investigated specimens were recorded by the $\mathrm{BK} 4393 \mathrm{~A}_{1}$ and $\mathrm{A}_{2}$ piezoelectric accelerometers (Brüel and Kjær, Nærum, Denmark). The accelerometers have these parameters: the frequency ranges from 0.5 to $16,500 \mathrm{~Hz}$; the temperature range from -74 to $250{ }^{\circ} \mathrm{C}$; and the weight is $2.4 \mathrm{~g}$ [24]. Measurements of the transfer damping function were performed for different inertial masses $m$ (i.e., for 0,90 and $500 \mathrm{~g}$ ), which were located on the upper side of the harmonically loaded investigated samples (see Figure 1). Moreover, vibration damping properties of the investigated rubber samples with ground plane dimensions of $60 \mathrm{~mm} \times 60 \mathrm{~mm}$ were performed for three different thicknesses (i.e., for 10, 15, and $20 \mathrm{~mm}$ ) of these materials. The view of the experimental setup used for the vibration damping testing is shown in Figure 2. Each measurement was repeated 10 times at an ambient temperature of $22{ }^{\circ} \mathrm{C}$.

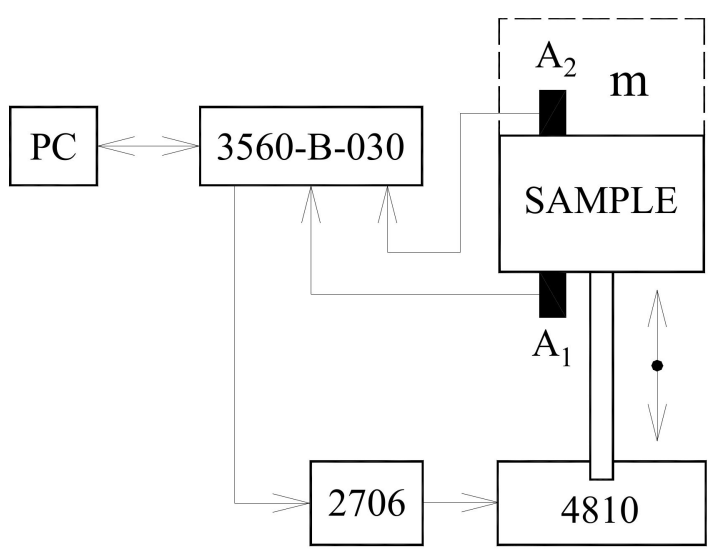

Figure 1. Schematic diagram of the measuring device.

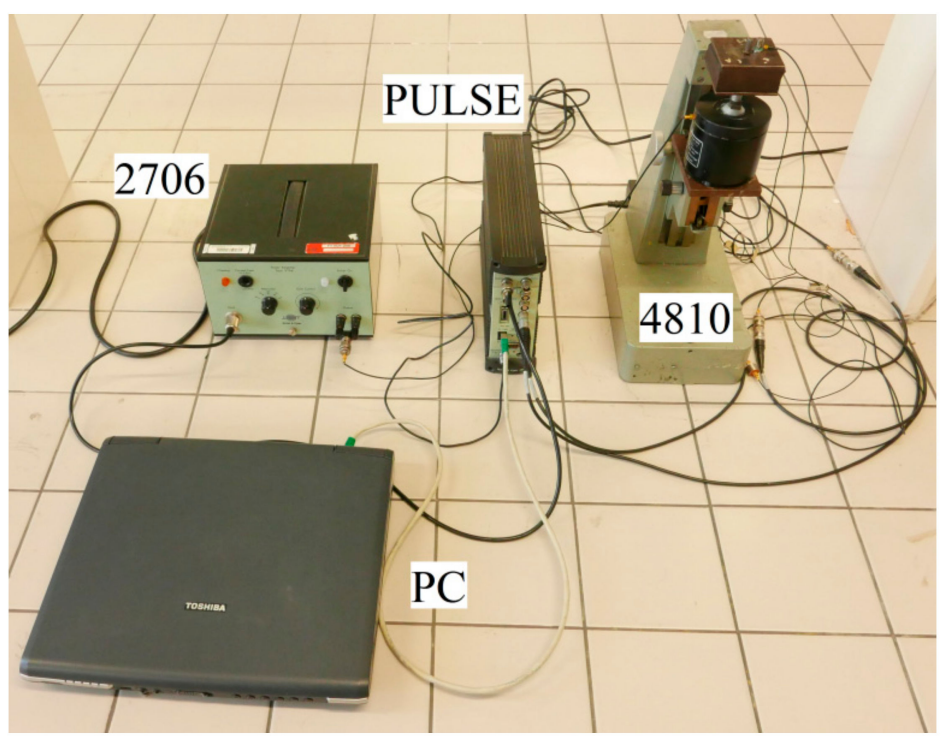

Figure 2. View of the experimental setup used for the vibration damping testing. Legend of the abbreviations: PC-personal computer; PULSE-signal pulse multi-analyzer; 2706-power amplifier; 4810-mini-shaker. 


\section{Results and Discussion}

\subsection{Curing Characteristics}

The curing characteristics of the mixed compounds are given in Table 2 . It is evident that the minimum torque $M_{L}$ significantly decreased with an increase in the primary carbon black particle size. This is caused by the decreasing amount of the immobilized rubber chains on the decreasing carbon black surface, as well as the structure. The low aggregate structure and surface area of the $\mathrm{N}$ 990 type leads to weak interaction with rubber chains. Moreover, the thermal production process leads to a higher purity of the carbon black surface, with low content of active groups. This fact can result in a lower stiffening effect. However, in the case of the torque $M_{L}$, interactions between rubber chains and carbon black are mainly caused by physical forces, because the property is in an uncured state [25-28].

Table 2. Curing characteristics of the studied compounds.

\begin{tabular}{cccccc}
\hline $\begin{array}{c}\text { Rubber } \\
\text { Type }\end{array}$ & $\begin{array}{c}\boldsymbol{M}_{\boldsymbol{L}} \\
{[\mathbf{N} \cdot \mathbf{m}]}\end{array}$ & $\begin{array}{c}\boldsymbol{M}_{\boldsymbol{H}} \\
{[\mathbf{N} \cdot \mathbf{m}]}\end{array}$ & $\begin{array}{c}\boldsymbol{\Delta} \boldsymbol{M} \\
{[\mathbf{N} \cdot \mathbf{m}]}\end{array}$ & $\begin{array}{c}\boldsymbol{t}_{\mathbf{s 1}} \\
{[\mathbf{m i n}]}\end{array}$ & $\begin{array}{c}\boldsymbol{t}_{\mathbf{9 0}} \\
{[\mathbf{m i n}]}\end{array}$ \\
\hline N 110 & 0.27 & 1.71 & 1.44 & 2.6 & 10.5 \\
N 330 & 0.24 & 1.45 & 1.21 & 2.6 & 11.5 \\
N 550 & 0.23 & 1.51 & 1.28 & 3.0 & 12.8 \\
N 990 & 0.12 & 1.07 & 0.95 & 3.3 & 12.6 \\
\hline
\end{tabular}

The difference between the maximum $\left(M_{H}\right)$ and the minimum $\left(M_{L}\right)$ torques is marked as $\Delta M$, which is a parameter demonstrating the degree of chemical crosslinking. The same amount and type of curing system was observed in the compounds; thus, the degree of $\Delta M$ is supposed to be comparable for all compounds. In reality, the $\Delta M$ is significantly different. Evidently, the reaction between the rubber and the curing system is one of the factors affecting the crosslinking process [28,29].

The other factor affecting the crosslinking process is the chemical reaction of the rubber with functional groups on the carbon black surface, which differs depending on the carbon black grade. It was found that these functional groups could have either positive or negative effects on the curing characteristics, depending on carbon black type [29]. Although the N 330 type has a higher surface area compared to the N 550 type, its curing level is lower due to the presence of cure-retarding groups [30]. This phenomenon causes various $t_{90}$ values for the compounds in this study.

\subsection{Quasi-Static Test Results}

The parameters of mechanical properties of the SBR and carbon black compounds are presented in Table 3. The hardness testing is the most obvious mechanical test. In this case, the Shore A hardness was measured. The obtained hardness results decreased from 69 to 55 Shore A and corresponded to the carbon black particle size, ranging from the largest specific surface (N 110) to the smallest one (N 990). The higher specific surface led to a harder rubber compound. It is evident from the above results that the hardness generally decreased with a decrease in the carbon black surface area.

Table 3. Mechanical properties of the rubber compounds.

\begin{tabular}{cccccc}
\hline $\begin{array}{c}\text { Rubber } \\
\text { Type }\end{array}$ & $\begin{array}{c}\text { Shore A } \\
\text { [Sh A] }\end{array}$ & $\begin{array}{c}\text { Stress at Break } \\
\text { [MPa] }\end{array}$ & $\begin{array}{c}\text { Strain at Break } \\
{[\%]}\end{array}$ & $\begin{array}{c}\mathbf{3 0 0 \%} \\
\text { Modulus } \\
{[\mathbf{M P a}]}\end{array}$ & $\begin{array}{c}\text { Resilience } \\
{[\%]}\end{array}$ \\
\hline N 110 & $69 \pm 1$ & $23.0 \pm 1.4$ & $480 \pm 36$ & $13.0 \pm 1.3$ & $38 \pm 1$ \\
N 330 & $66 \pm 1$ & $23.9 \pm 0.9$ & $520 \pm 23$ & $12.7 \pm 1.0$ & $39 \pm 1$ \\
N 550 & $64 \pm 1$ & $19.8 \pm 0.5$ & $510 \pm 25$ & $11.9 \pm 0.5$ & $44 \pm 1$ \\
N 990 & $55 \pm 1$ & $11.9 \pm 2.7$ & $640 \pm 75$ & $4.1 \pm 0.4$ & $51 \pm 1$ \\
\hline
\end{tabular}


The tensile test was performed in order to characterize the basic mechanical properties of the rubber compounds. It should be noted that the compounds containing the carbon black with small primary particles ( 110 and N 330) showed the highest break stress (about $23 \mathrm{MPa}$ ), while the elongation was the lowest. The increasing primary carbon black particle size causes the decrease of the break stress. This is caused by the reinforcing ability of the carbon black particle size. The smaller primary particle sizes led to a higher specific surface area and to a stronger restriction of the elastomer chain mobility.

Here, the $300 \%$ modulus is the parameter characterizing the stiffness of rubber vulcanizates, representing the stress at $300 \%$ extension. In addition to previous parameters, it is influenced by the carbon black surface area. The highest value for this modulus was obtained for the N 110 type. The $300 \%$ modulus decreased with a decrease in the surface area as well.

The rebound resilience increased from $38 \%$ up to $51 \%$ for N 110 and N 990 carbon black types, respectively. Additionally, this property is influenced by the particle size, and thus, by the surface area of the carbon black. The stiffening effect of the N 110 type is stronger in comparison to the others. It provides harder rubber with lower rebound elasticity, because a larger part of the mechanical energy is transformed into heat.

Theoretically, the mechanical properties should show greater differences between the N 110 and N 330 carbon black types. Unfortunately, mechanical properties are strongly influenced by the level of filler dispersion in the matrix, which also depends on the carbon black particle size. With decreasing particle size, more energy is required to achieve high filler dispersion. Thus, a shorter mixing time leads to poorer filler dispersion. For this reason, the mechanical properties are reduced. On the other hand, a longer mixing time can cause polymer chain scission and also a decrease in the final properties. For this study, the rubber compounds were prepared under constant mixing conditions.

\subsection{Dynamical Mechanical Properties}

The effects of various carbon blacks in the SBR matrix on the temperature dependence of the elastic (storage) modulus is summarized in Figure 3. These curves describe the temperature region, where the hard and brittle material behavior is replaced by the rubbery or viscoelastic behavior. The modulus decreased strongly in the glassy transition region. The elastomer chain mobility, and thereby the glass temperature, is noticeably affected by various additives in the rubber compound. The presence of filler, the amount, an increase in the surface area, or the structure can restrict the chain's movement ability and lead to the shift of the glassy region to higher or lower temperatures [9].

During heating, the elastic modulus of the studied compounds decreased in the temperature range from $-50{ }^{\circ} \mathrm{C}$ to $-25^{\circ} \mathrm{C}$. The most rapid decrease of the elastic modulus was observed for the compound containing the $\mathrm{N} 990$ carbon black type. On the other hand, the highest values of the elastic modulus were obtained for the compounds with the N 110 and N 330 carbon black types. This is connected with the decreasing carbon black particle sizes and the increasing surface area.

The glass transition temperature for the rubber compounds determined from the loss factor $(\tan \delta)$ curve of three measurements was in the low temperature region, namely $-31.9 \pm 0.6{ }^{\circ} \mathrm{C},-32.5 \pm 0.5{ }^{\circ} \mathrm{C}$, $-32.2 \pm 0.6{ }^{\circ} \mathrm{C}$, and $31.1 \pm 0.8^{\circ} \mathrm{C}$ for the $\mathrm{N} 110, \mathrm{~N} \mathrm{330,N} \mathrm{550,} \mathrm{and} \mathrm{N} 990$ types, respectively (see Figure 4). The differences in the glass temperature between compounds were less than $10 \%$. The shift in glass transition temperature was probably caused by sample thickness inhomogeneity and the slightly different clamping forces of each compound. As a result, no significant effect was observed for the particle size on the glass transition temperature. In addition, the damping properties of the rubber compounds can be evaluated from this figure. It is evident that the loss factor increased with an increase in the primary particle size. 


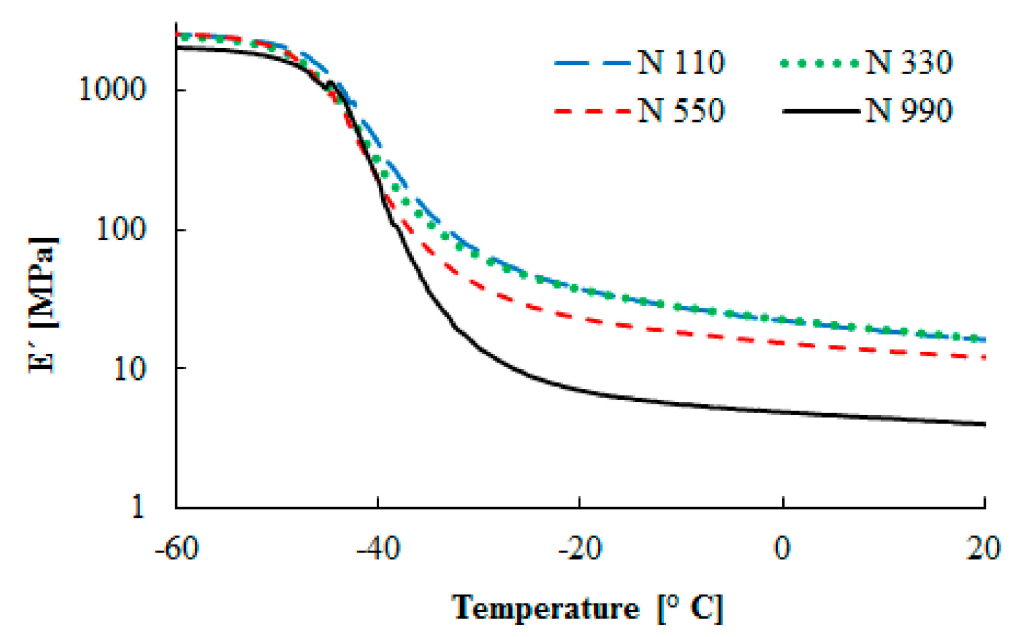

Figure 3. Temperature dependence of the tensile storage modulus.

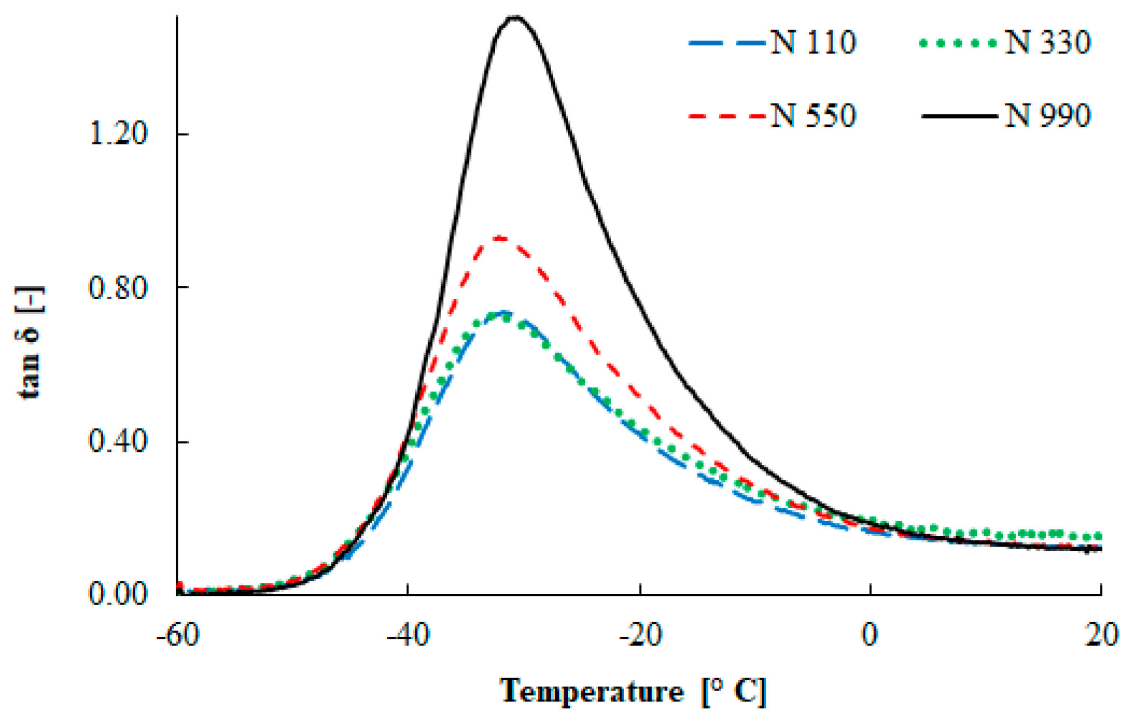

Figure 4. Temperature dependence of the loss factor.

The dynamic stiffness of the tested rubber mixtures is measured by the complex modulus of elasticity. The frequency dependencies of the storage modulus and the loss factor at $25{ }^{\circ} \mathrm{C}$ are demonstrated in Figures 5 and 6.

Significant changes of the storage modulus depending on the frequency for SBR compounds with the N 110, N 330, and N 550 carbon blacks are evident in Figure 5. There is a moderate increase of the storage modulus with the frequency up to $180 \mathrm{~Hz}$. The filler with the smallest primary particle size (N 110) exhibited the highest storage modulus values, while N 990 gave the lowest values. This is connected with the filler-polymer interaction. This fact depends on the filler's primary particle size, as well as its structure [28].

It was found that the loss factor $\tan \delta$ at low frequencies up to $100 \mathrm{~Hz}$ showed similar behavior for all carbon black compounds (see Figure 6). Generally, the loss factor increased with an increase in the frequency. While for the more reinforced carbon black type (N 110) the increase of $\tan \delta$ was slower, in the case of the $\mathrm{N} 990$ type the loss factor increased more significantly. 


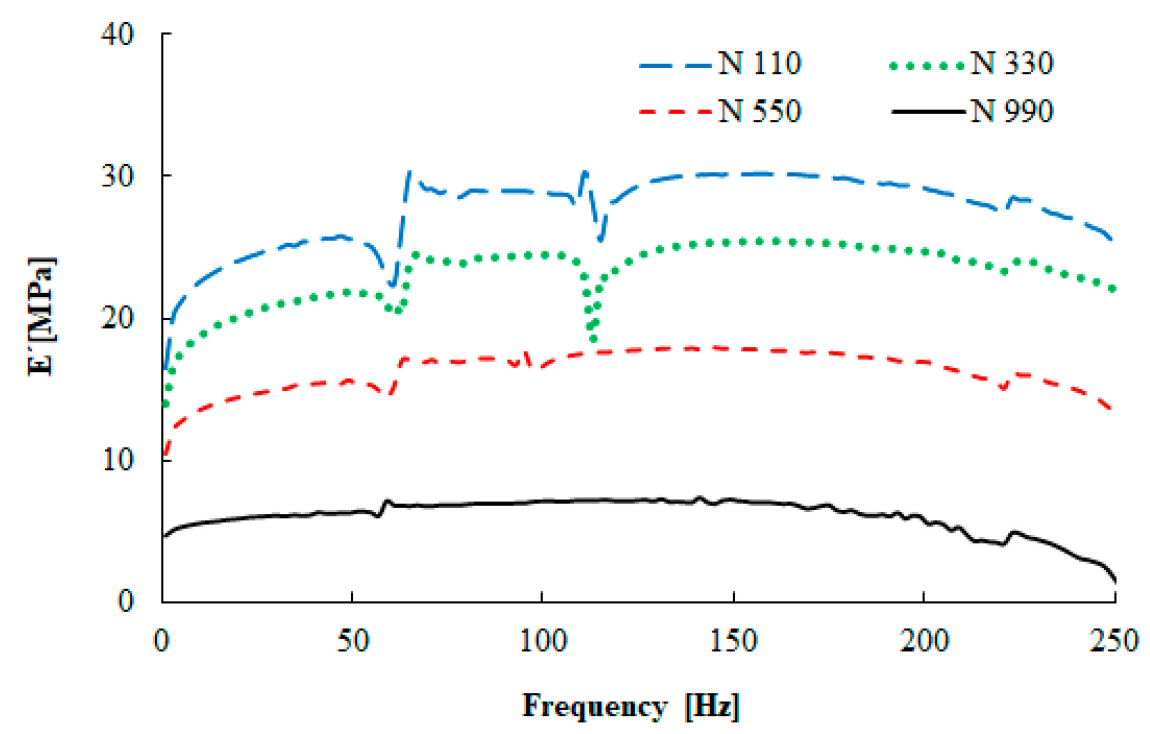

Figure 5. Frequency dependence of the tensile storage modulus (displacement $x=5 \mu \mathrm{m}, \mathrm{T}=25^{\circ} \mathrm{C}$ ).

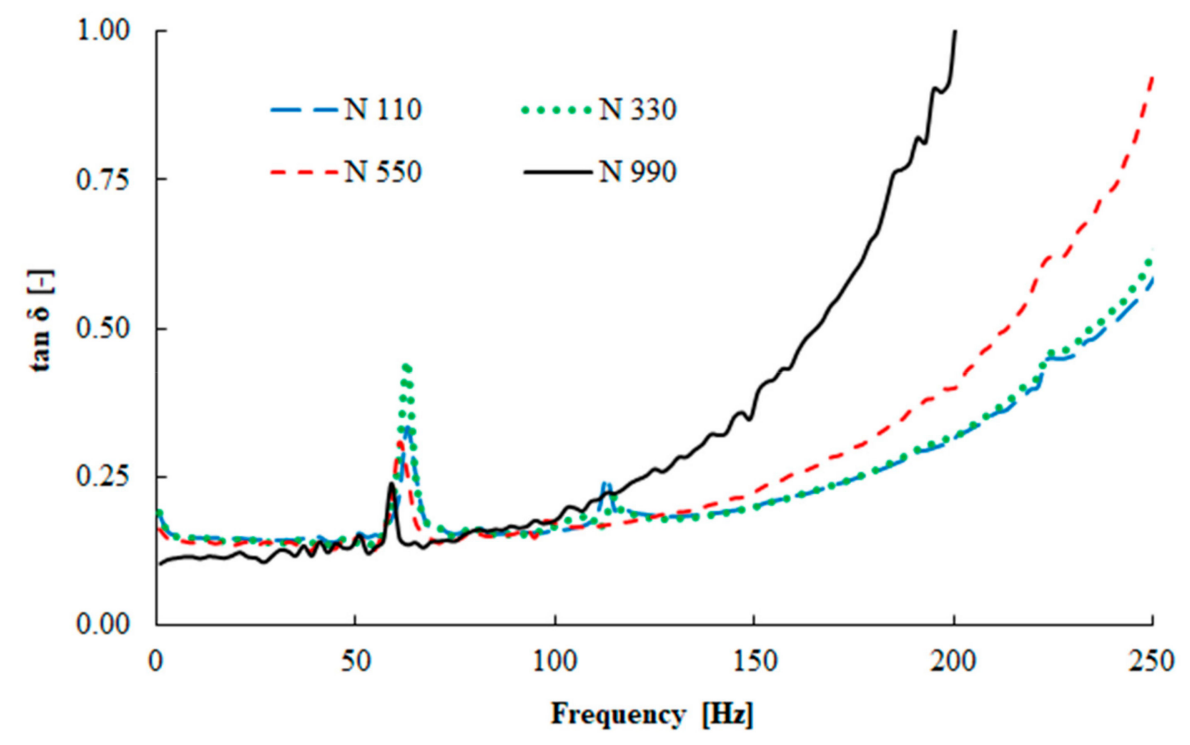

Figure 6. Frequency dependence of the loss factor (displacement $\mathrm{x}=5 \mu \mathrm{m}, \mathrm{T}=25^{\circ} \mathrm{C}$ ).

The next measurement was performed in order to evaluate the deformation dependence of the tested samples on their dynamic properties. The elastic modulus dependence on the displacement is shown in Figure 7. The effects of the carbon black particle size and structure were measured by this experiment. The compound with the smallest primary particle size gave the highest elastic modulus value, while that with the largest particle sizes showed almost no stiffening effect and had almost constant elastic modulus during the whole deformation range. High elastic moduli at low deformation levels are caused by the filler-filler interaction, as explained by Payne [31]. The smallest particles with higher carbon black structures created stronger filler-filler network in comparison with larger particles and a lower carbon black structures. With the increasing deformation, the filler network is destroyed and the interaction between the rubber and carbon black becomes the main factor.

Incorporated carbon black particles, which are already known as aggregates, create a filler-filler network. Inside the rubber compound, carbon black aggregates are formed by van der Waals forces into so called agglomerates. If a small deformation is applied, a high elastic modulus value is obtained.

The reason for this phenomenon is the strong interaction between filler particles that are not broken. From Payne's point of view, some of the rubber is immobilized on the filler surface, and in addition some of the rubber is also immobilized inside the branched structure of the agglomerate 
(known as occluded rubber). If the deformation increases, the agglomerates are broken into smaller sizes, and therefore the elastic modulus decreases. This phenomenon is caused by more mobile smaller units inside the rubber compound. At high deformation levels a plateau can be reached, whereby individual mobile aggregates units are set into motion. This behavior is known as the Payne effect [31-36].

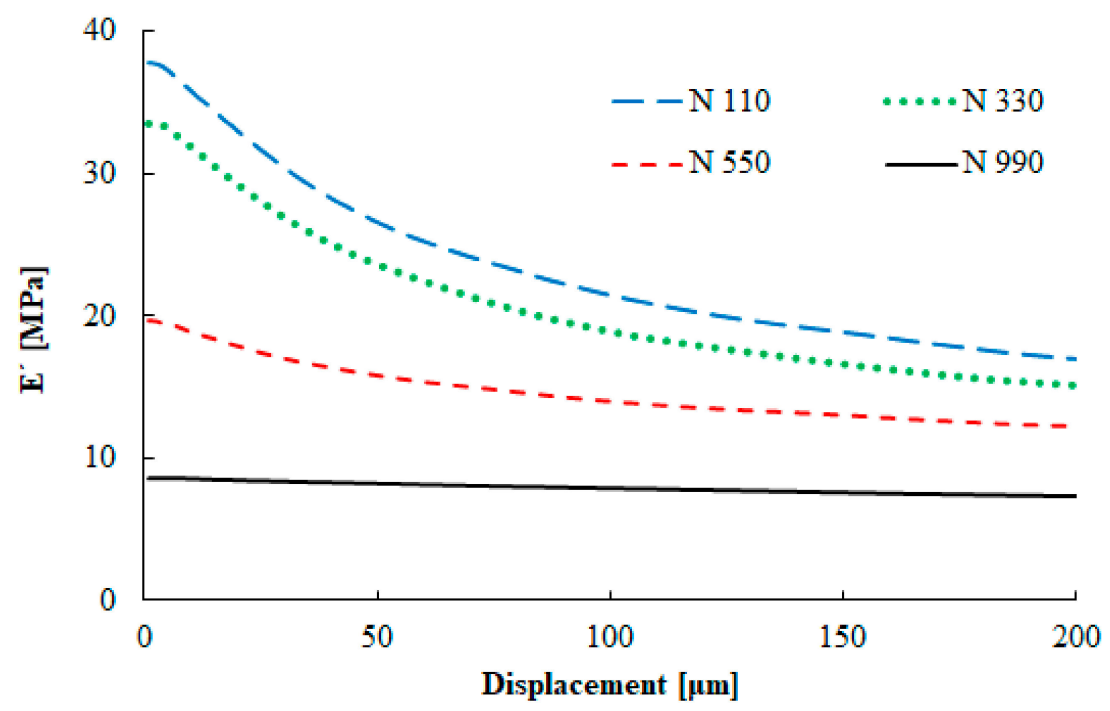

Figure 7. Displacement dependence of the tensile storage modulus $\left(\mathrm{f}=20 \mathrm{~Hz}, \mathrm{~T}=0{ }^{\circ} \mathrm{C}\right)$.

The dependence of the loss modulus on the sample deformation is presented in Figure 8. The loss modulus increased with a decrease in the primary particle size. The stronger filler-filler interaction led to higher energy dissipation. With the increasing deformation, the loss modulus maximum was found around the displacement amplitude of $35 \mu \mathrm{m}$ for the compounds with the $\mathrm{N} 110$ and $\mathrm{N} 330$ carbon black types. The highest damping properties were obtained in this area. Apparently, the values of the loss modulus were low for the N 550 and N 990 carbon black types, while damping properties were especially negligible for the $\mathrm{N} 990$ type.

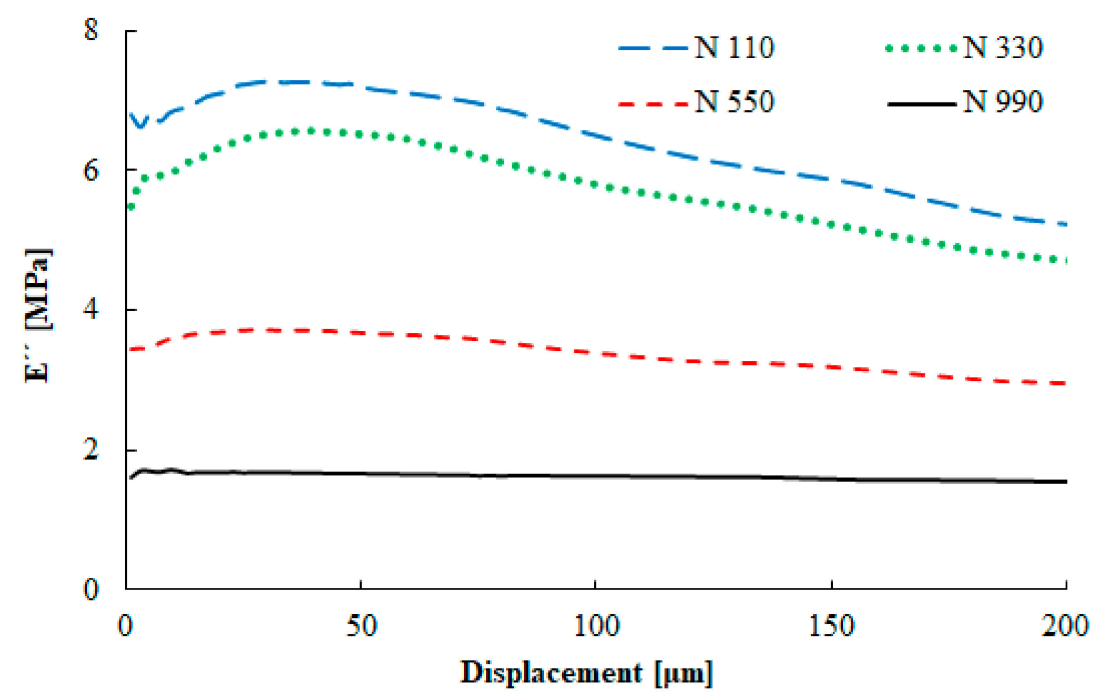

Figure 8. Displacement dependence of the tensile loss modulus $\left(f=20 \mathrm{~Hz}, \mathrm{~T}=0{ }^{\circ} \mathrm{C}\right)$.

Shear amplitude deformation was measured using a rubber process analyzer. This test describes similar behavior of the rubber compounds as the DMA measurements, but in shear deformation mode. 
The dependence of the filler-filler interaction for compounds with the N 110, N 330, N 550, and N 990 carbon black types is depicted in Figure 9. A strong dependence of the shear storage modulus on the filler particle size is visible, similarly to the DMA testing. Large carbon black particles (N 990) are characterized by a low reinforcing effect, while small particles (N 110) cause a pronounced increase of the storage modulus. Figure 10 shows the strain amplitude dependence of the loss modulus of four carbon black grades. Similarly to the DMA measurements, the shear loss modulus was highest for the $\mathrm{N} 110$ type, while for the $\mathrm{N} 990$ type it was the lowest. The maximum value of the loss modulus was observed at $1 \%$ strain, which is fully connected with the maximal damping properties.

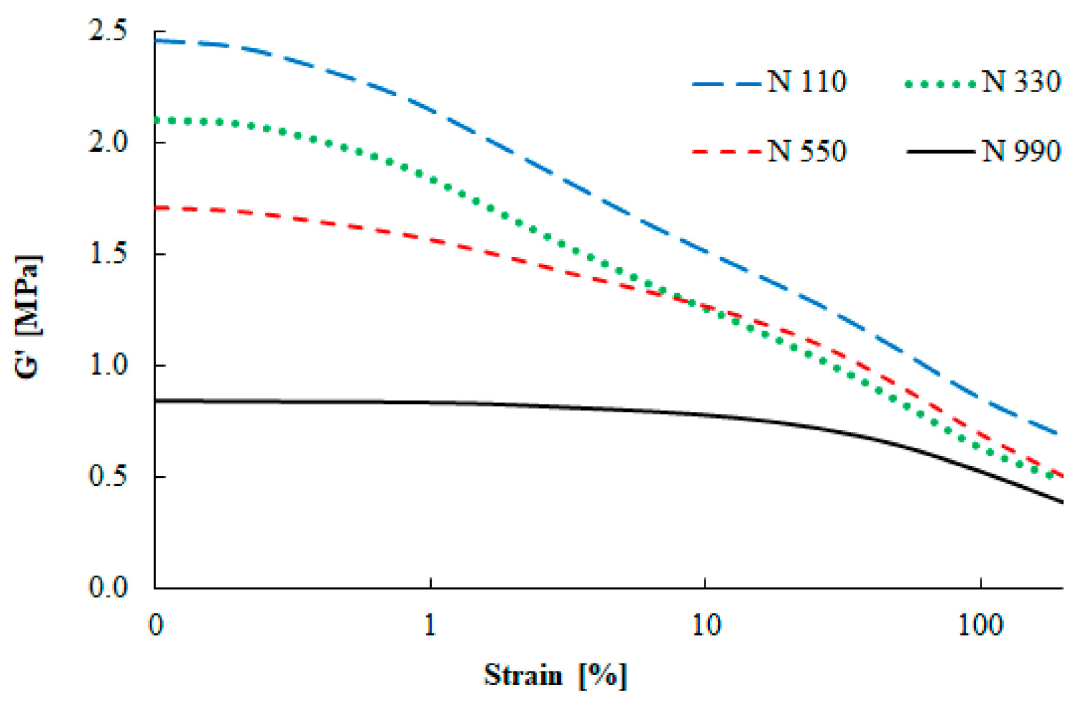

Figure 9. Strain amplitude dependence of the shear storage modulus.

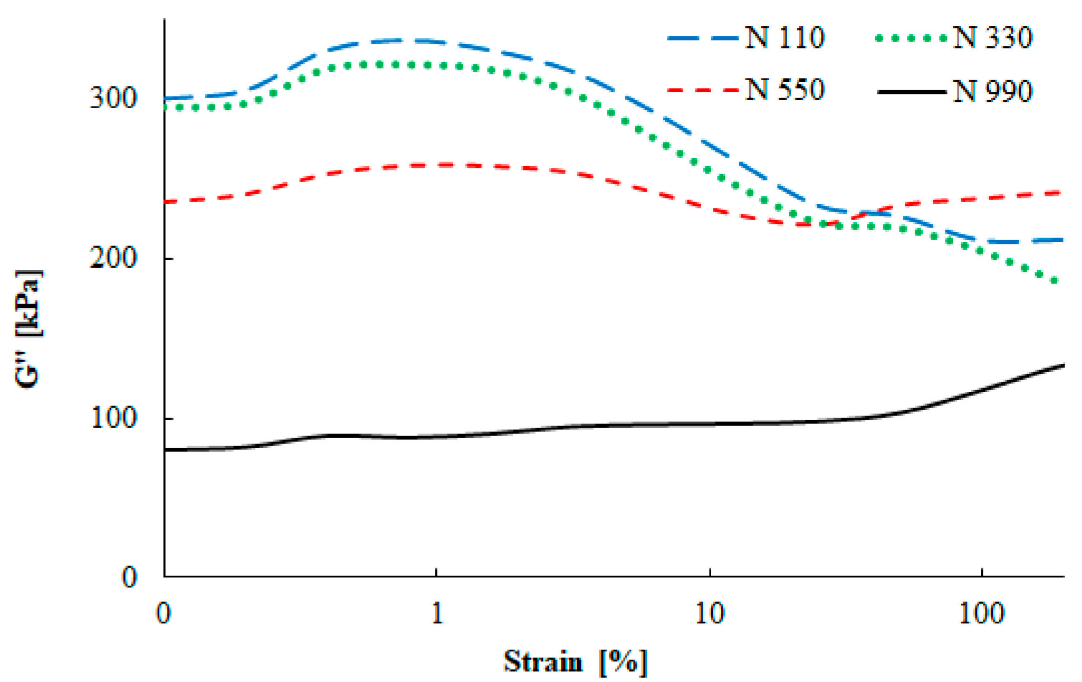

Figure 10. Strain amplitude dependence of the shear loss modulus.

\subsection{The Hysteresis Characteristics}

Due to the viscoelastic nature of the rubber vulcanizates, the stress-strain curves of the tested rubber create a hysteresis loop during the loading and unloading cycles. The hysteresis loop area corresponds to the energy dissipated into heat. The heat generation inside the rubber mixture can lead to it softening and even rupturing. The heat generation is affected by the polymer nature, curing level, and compound composition. This behavior is also known as the Mullins effect.

The hysteresis loops for the studied compounds are presented in Figure 11. The rubber was dynamically loaded in compression mode during 100 loading cycles. In this figure, the last cycle is 
recorded. Evidently, there are quite large differences among the carbon black types added to each compound. The largest area of the hysteresis loop was achieved for the N 110 carbon black type, which had the highest specific surface area, while the lowest heat generation was obtained for the N 990 type. An explanation of this phenomena was given by Fukahori [36]. According to this theory, rubber covers the carbon black surface in creation of the so-called bound rubber. This is an immobilized part of the rubber macromolecules that is physically connected with carbon black particles. During the loading of a polymer-carbon black structure, the orientation of this structure appears. If the unloading process is applied, the stress decreases faster compared to common macromolecular stress relaxation, and the decrease in the unloading curve is visible.
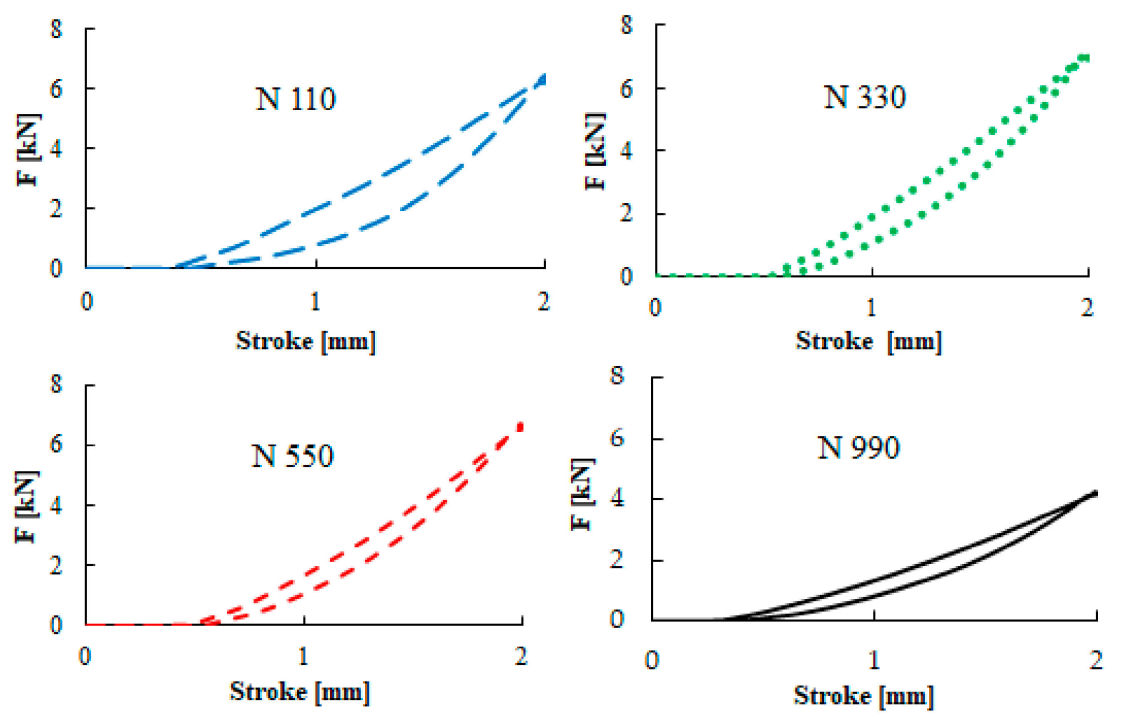

Figure 11. Hysteresis images of four carbon black types.

\subsection{Vibration Damping Properties}

Examples of the frequency dependencies of the transfer damping function of the tested rubber composites measuring $t=10 \mathrm{~mm}$ in thickness with different carbon black particle sizes are shown in Figure 12. It is evident from this comparison that the size of the carbon black particles has a significant influence on the vibration damping properties. It can be concluded that the material's ability to damp mechanical vibration generally increased with an increase in the carbon black particle size. This is caused by lower stiffness (or by higher damping) of the rubber composites, which were produced with larger carbon black particle sizes. These facts result in a higher transformation of input mechanical energy into heat during forced oscillations [37] and a decrease in the values of the damped and undamped natural frequencies [38]. Therefore, the first resonance frequency $\left(f_{R 1}\right)$ value was shifted to the left (see Figure 12) with an increase in the carbon black particle size, i.e., from 1520 (N 110) to $968 \mathrm{~Hz}$ (N 990), as indicated in Table 4. These findings are in excellent agreement with the results that were experimentally determined by the abovementioned methods, namely the hardness, tensile, shear, and viscoelastic measurements. It was verified in these cases that the increasing carbon black particle size led to a decrease of the break stress, the Shore A hardness, and the storage moduli $E^{\prime}$ and $G^{\prime}$. In contrast, the rebound resilience was higher for these particle sizes. 
Table 4. The first resonance frequency $\left(f_{R 1}\right)$ in $\mathrm{Hz}$ of the studied rubber composite materials, as induced by harmonic force vibration for different rubber thicknesses and inertial masses.

\begin{tabular}{ccccc}
\hline \multirow{2}{*}{$\begin{array}{c}\text { Rubber } \\
\text { Type }\end{array}$} & $\begin{array}{c}\text { Thickness } \\
{[\mathbf{m m}]}\end{array}$ & $\mathbf{0}$ & $\mathbf{9 0}$ & $\mathbf{5 0 0}$ \\
\cline { 3 - 5 } & 10 & $1520 \pm 41$ & $1146 \pm 18$ & $430 \pm 15$ \\
N 110 & 15 & $1293 \pm 29$ & $1043 \pm 18$ & $419 \pm 14$ \\
& 20 & $1080 \pm 15$ & $928 \pm 17$ & $354 \pm 12$ \\
\hline \multirow{3}{*}{ N 330 } & 10 & $1441 \pm 32$ & $1138 \pm 19$ & $412 \pm 14$ \\
& 15 & $1242 \pm 22$ & $957 \pm 16$ & $402 \pm 13$ \\
& 20 & $881 \pm 16$ & $520 \pm 15$ & $320 \pm 9$ \\
\hline & 10 & $1404 \pm 27$ & $900 \pm 18$ & $379 \pm 13$ \\
& 15 & $977 \pm 18$ & $737 \pm 16$ & $288 \pm 10$ \\
& 20 & $718 \pm 16$ & $456 \pm 12$ & $233 \pm 8$ \\
\hline & 10 & $968 \pm 20$ & $848 \pm 16$ & $298 \pm 10$ \\
& 15 & $802 \pm 19$ & $635 \pm 15$ & $258 \pm 9$ \\
& 20 & $693 \pm 15$ & $310 \pm 11$ & $231 \pm 7$ \\
\hline
\end{tabular}

The vibration damping properties of the investigated harmonically loaded composite rubber samples are also influenced by their thickness $t$, the excitation frequency $f$, and the inertial mass $m$. The effect of the inertial mass on the vibration damping properties of sample $\mathrm{N} 330$ is shown in Figure 13. It is visible that better damping properties were obtained with higher inertial mass $m$, which led to a decrease in the undamped natural frequency, and thus, the damped frequency. This is due to the fact that the natural frequency of an undamped system is proportional to the square root of the material stiffness for the applied inertial mass [22]. For this reason, the inertial mass has a positive influence on vibration damping, which is reflected by a shift of the first resonance frequency peak position to lower frequencies, i.e., by the decrease of the $f_{R 1}$ (see Table 4$)$ from $1441(m=0 \mathrm{~g})$ to $412 \mathrm{~Hz}(m=500 \mathrm{~g})$. The vibration isolation properties of the investigated rubber composites are also significantly influenced by their thickness $t$, as shown in Figure 14 for the N 330 sample with an inertial mass $m$ of $90 \mathrm{~g}$. It is evident that the higher material thickness led to lower values of the $f_{R 1}$, i.e., from $1138(t=10 \mathrm{~mm})$ to $520 \mathrm{~Hz}(t=20 \mathrm{~mm})$, as indicated in Table 4. For this reason, the rubber thickness generally has a positive influence on vibration damping properties. It is also visible from Figures 12-14 that the material's ability to damp mechanical vibration is significantly influenced by the excitation frequency $f$. It is evident that resonant mechanical vibration $(D<0)$ was achieved at low excitation frequencies, depending on the rubber sample type, the thickness $t$, and the inertial mass $m$. For example, for the $\mathrm{N} 110$ sample type measuring $t=10 \mathrm{~mm}$ in thickness and without inertial mass $(m=0 \mathrm{~g})$, the resonant mechanical vibration was observed at frequencies $f<2950 \mathrm{~Hz}$ (see Figure 12). For the $\mathrm{N} 990$ sample type measuring $t=20 \mathrm{~mm}$ in thickness and with inertial mass $m=500 \mathrm{~g}$, the resonant mechanical vibration was achieved at considerably lower excitation frequencies (at $f<330 \mathrm{~Hz}$ ). In contrast, damped mechanical vibration $(D>0)$ was generally achieved at higher excitation frequencies (see Figures 12-14).

The material's ability to damp mechanical vibration was also evaluated for the tested material samples, which were harmonically loaded by the compression force with an amplitude of $10 \mathrm{kN}$ at an excitation frequency of $20 \mathrm{~Hz}$. In the case of the N 990 sample type, it was not possible to perform this evaluation due to the low stiffness of this rubber sample compared to the other tested rubber sample types. The frequency dependencies of the transfer damping function of the investigated rubber samples (thickness $t=20 \mathrm{~mm}$, inertial mass $m=90 \mathrm{~g}$ ) after 750,000 loading cycles are demonstrated in Figure 15. Again, as in the case of the cyclically unloaded rubber samples (see Figure 12), the material's ability to dampen mechanical vibration increased with an increase in the carbon black particle size. For this reason the rubber composites, which were produced with larger carbon black particle sizes, exhibited lower stiffness, resulting in a decrease of the first resonance frequency peak position to lower 
excitation frequencies. As shown in Table 5, similar results were obtained independently of the number of loading cycles.

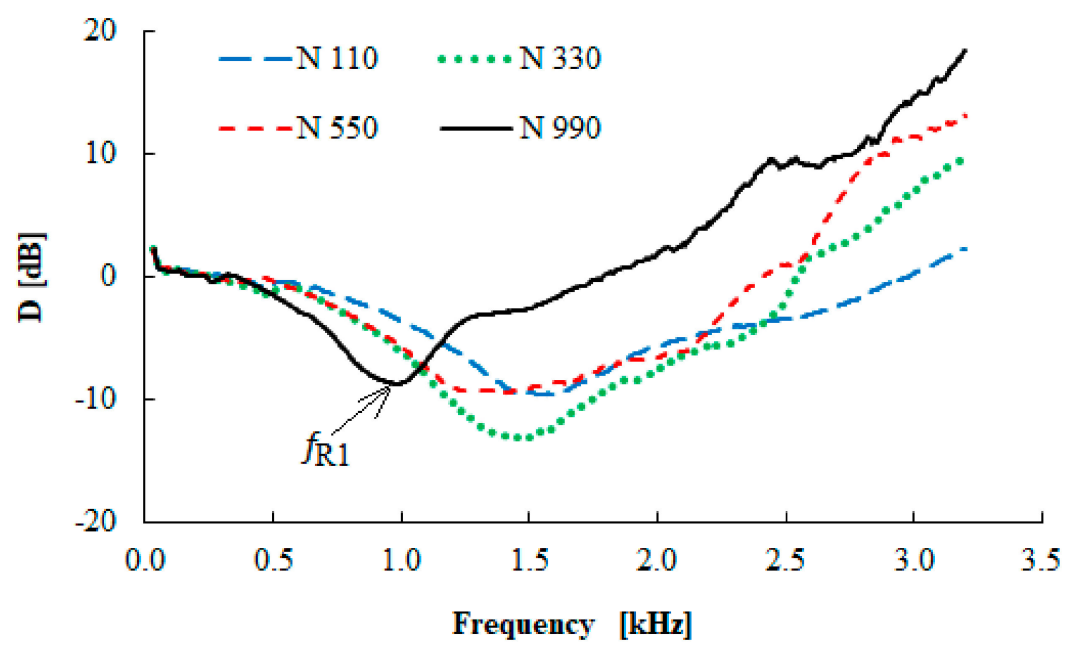

Figure 12. Frequency dependence of the transfer damping function (D) for the tested rubber composite measuring $\mathrm{t}=10 \mathrm{~mm}$ in thickness, without inertial mass $(\mathrm{m}=0 \mathrm{~g})$.

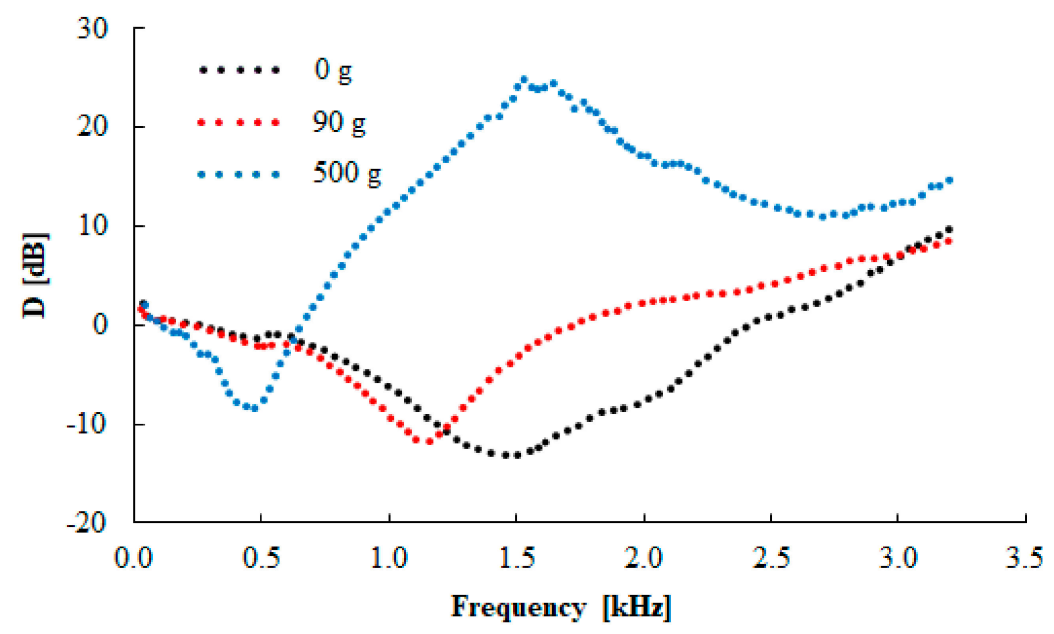

Figure 13. Frequency dependencies of the transfer damping function (D) for the tested N 330 rubber composite measuring $\mathrm{t}=10 \mathrm{~mm}$ in thickness, loaded with different inertial masses.

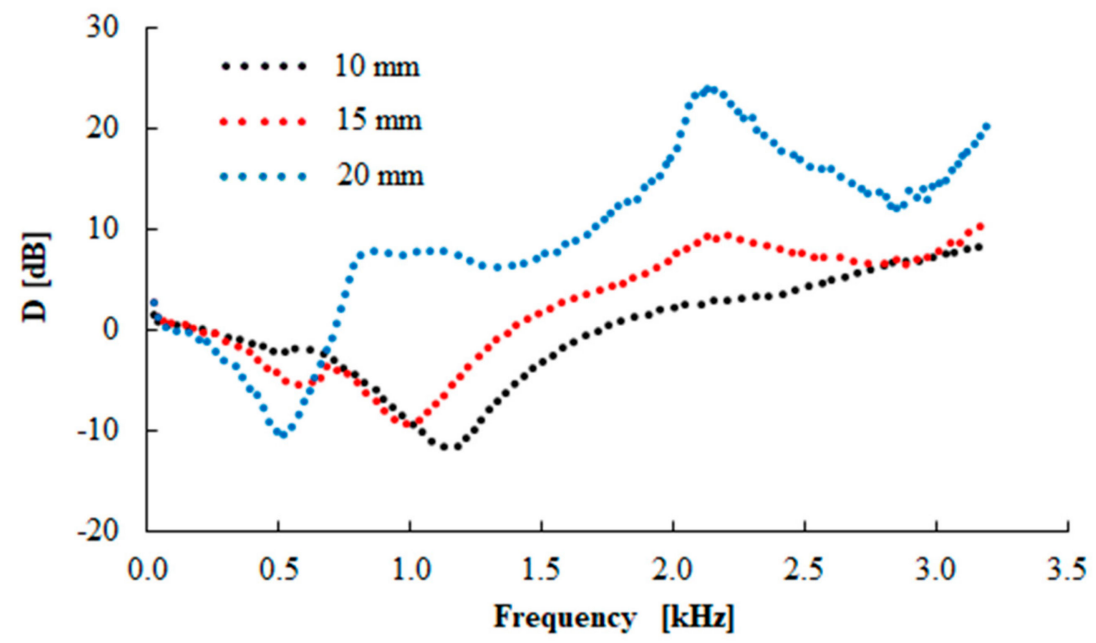

Figure 14. Frequency dependencies of the transfer damping function (D) for the tested N 330 rubber composites of different thicknesses and loaded with inertial mass $\mathrm{m}=90 \mathrm{~g}$. 
Table 5. The first resonance frequency $\left(f_{R 1}\right)$ in $\mathrm{Hz}$ of the studied rubber composite materials measuring $t$ $=20 \mathrm{~mm}$ in thickness, as induced by harmonic force vibration for different inertial masses and numbers of loading cycles.

\begin{tabular}{ccccc}
\hline \multirow{2}{*}{ Number of Cycles } & Rubber & \multicolumn{3}{c}{ Inertial Mass [g] } \\
\cline { 3 - 5 } & Type & $\mathbf{0}$ & $\mathbf{9 0}$ & $\mathbf{5 0 0}$ \\
\hline \multirow{3}{*}{0} & N 110 & $1080 \pm 15$ & $928 \pm 17$ & $354 \pm 12$ \\
& N 330 & $881 \pm 16$ & $520 \pm 15$ & $320 \pm 9$ \\
& N 550 & $718 \pm 16$ & $456 \pm 12$ & $233 \pm 8$ \\
\hline \multirow{3}{*}{100,000} & N 110 & $1029 \pm 17$ & $563 \pm 14$ & $328 \pm 11$ \\
& N 330 & $534 \pm 15$ & $507 \pm 13$ & $301 \pm 10$ \\
& N 550 & $430 \pm 13$ & $378 \pm 11$ & $227 \pm 9$ \\
\hline \multirow{2}{*}{550,000} & N 110 & $482 \pm 15$ & $430 \pm 12$ & $245 \pm 10$ \\
& N 330 & $457 \pm 12$ & $405 \pm 11$ & $241 \pm 9$ \\
& N 550 & $381 \pm 10$ & $356 \pm 10$ & $192 \pm 8$ \\
\hline \multirow{2}{*}{500,000} & N 110 & $434 \pm 11$ & $388 \pm 10$ & $237 \pm 8$ \\
& N 330 & $399 \pm 11$ & $371 \pm 11$ & $231 \pm 8$ \\
& N 550 & $372 \pm 10$ & $237 \pm 9$ & $140 \pm 6$ \\
\hline \multirow{2}{*}{750,000} & N 110 & $404 \pm 12$ & $380 \pm 11$ & $208 \pm 8$ \\
& N 330 & $374 \pm 11$ & $338 \pm 10$ & $158 \pm 7$ \\
& N 550 & $360 \pm 11$ & $214 \pm 8$ & $126 \pm 5$ \\
\hline
\end{tabular}

The effect of the number of loading cycles on the vibration damping properties of the $\mathrm{N} 330$ sample type is shown in Figure 16. It is evident that the vibration damping ability of the sample generally increased with an increase in the number of loading cycles, which led to a decrease of the first resonance frequency peak position to lower frequency values (see Table 5) with the increasing number of loading cycles. Therefore, the higher number of loading cycles led to a reduction in rubber sample stiffness, which was accompanied by better damping properties in this rubber sample. As shown in Table 5, similar findings were observed for the other tested rubber composites.

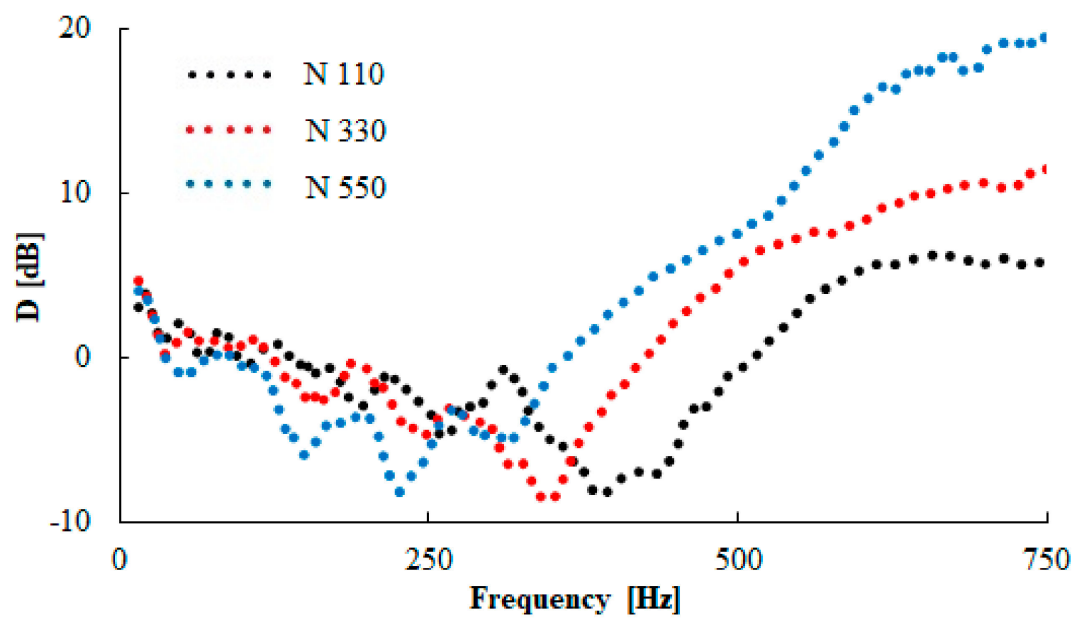

Figure 15. Frequency dependencies of the transfer damping function (D) for the tested rubber composites measuring $\mathrm{t}=20 \mathrm{~mm}$ in thickness after 750,000 loading cycles, with inertial mass $\mathrm{m}=90 \mathrm{~g}$. 


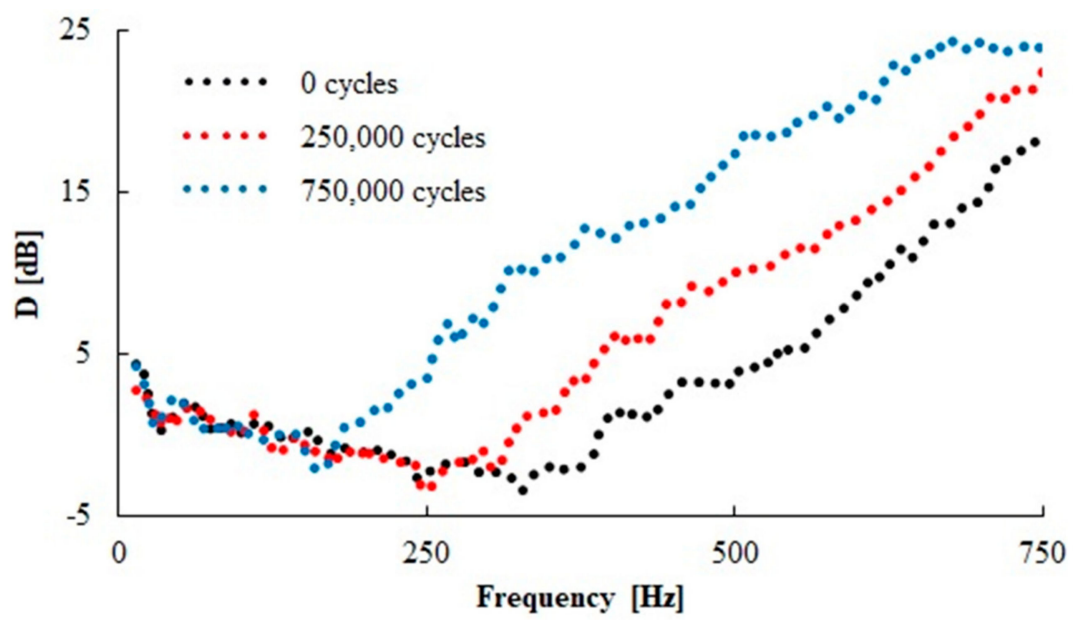

Figure 16. Effect of number of loading cycles on frequency dependencies of the transfer damping function (D) for the N 330 rubber composite measuring $t=20 \mathrm{~mm}$ in thickness, with inertial mass $\mathrm{m}=500 \mathrm{~g}$.

\section{Conclusions}

Mechanical vibrations are currently undesirable in many cases. Therefore, this vibration must be eliminated in appropriate ways. One of the possible elimination methods is the application of suitable vibro-insulating materials. This paper was focused on the study of the mechanical and vibro-isolation properties of rubber compounds containing different carbon black particle sizes. Nevertheless, their volume concentration was the same. On the basis of the evaluated measurements, it can be stated that the particle size of the carbon black in the rubber composites had a significant effect on the stiffness of the rubber, and thus on its mechanical and vibro-isolation properties.

The mechanical properties of the tested rubber mixtures were investigated for reflective elasticity, tensile, viscoelastic, and vibro-insulating properties. It was found in this work that the stiffness of the rubber samples generally decreased with an increase in the particle size, resulting in higher reflective elasticity and lower mechanical properties, including lower hardness (decrease from 69 to $55 \mathrm{Sh} \mathrm{A}$ ), breaking stress, and real components of the complex modulus of elasticity (tensile and shear). On the other hand, the higher particle size in the rubber mixtures led to a greater loss factor and deformations in terms of sample breakage.

The above facts were in good agreement with the vibro-isolation tests for the observed rubber materials, which were examined using the forced oscillation method based on the transfer damping function. At the same time, a material's ability to dampen mechanical vibrations under dynamic stress is associated with the first resonance frequency, which is generally lower for materials that better dampen mechanical oscillation (or for materials with lower stiffness). Based on this method, it was verified that the first resonant frequency generally decreased with an increase in the carbon black particle size. Therefore, larger carbon black particles of the same volume concentration in rubber patterns contributed to better damping of mechanical vibrations, resulting in a higher transformation of input mechanical energy into heat under dynamic loading of these rubber composite samples. Vibration damping properties were also evaluated for the investigated rubber samples, which were harmonically loaded by a compression force. It can be concluded that a higher number of loading cycles led to a stiffness reduction in the investigated rubber composites, which was accompanied by a shift of the first resonance frequency peak position to lower excitation frequencies. Depending on the rubber type and the inertial mass, the decrease of the first resonance frequency after 750,000 loading cycles was between $37 \%$ and $65 \%$. Furthermore, it has been found in this work that the material's ability to damp mechanical vibrations generally increased with an increase in the excitation frequency of mechanical vibration, inertial mass, and thickness of the investigated rubber samples. 
Author Contributions: Conceptualization, M.P. and M.V.; methodology, M.P., M.V., and P.Z.; preparation of rubber composites, P.Z. and M.P.; experimentation, P.Z., M.P., M.V., and M.Ž.; data analysis, P.Z., M.P., and M.V.; resources, M.V. and M.P.; writing-original draft preparation, M.V., M.P., and D.M.; writing-review and editing, M.V., M.P., D.M., and P.Z. All authors have read and agreed to the published version of the manuscript.

Funding: This work was supported by the Research Center of Advanced Mechatronic Systems project, number CZ.02.1.01/0.0/0.0/16_019/0000867, within the Operational Program of Research, Development, and Education; and by grant IGA/FT/2018/008 and grant NPU I LO1504.

Conflicts of Interest: The authors declare that they have no conflicts of interest.

\section{References}

1. Stephen, N. On energy harvesting from ambient vibration. J. Sound Vib. 2006, 293, 409-425. [CrossRef]

2. Lapcik, L.; Cetkovsky, V.; Lapcikova, B.; Vasut, S. Materials for noise and vibration attenuation. Chem. Listy 2000, 94, 117-122.

3. Sakakibara, S. Properties of vibration with fractional derivative damping of order 1/2. JSME Int. J. Ser. C Mech. Syst. Mach. Elem. Manuf. 1997, 40, 393-399. [CrossRef]

4. Lee, K.H.; Kim, C.M. Application of viscoelastic damping for passive vibration control in automotive roof using equivalent properties. Int. J. Automot. Technol. 2005, 6, 607-613.

5. Elias, S. Seismic energy assessment of buildings with tuned vibration absorbers. Shock. Vib. 2018, 2018, 1-10. [CrossRef]

6. Qin, C.; Zhao, D.; Bai, X.; Zhang, X.; Zhang, B.; Jin, Z.; Niu, H. Vibration damping properties of gradient polyurethane/vinyl ester resin interpenetrating polymer network. Mater. Chem. Phys. 2006, 97, 517-524. [CrossRef]

7. Lee, H.J.; Lee, B.G.; Shin, D.Y. Vibration and impact noise damping properties of wood/polymer composites. Mater. Sci. Forum 2005, 486, 358-361. [CrossRef]

8. Goto, A.; Maekawa, Z.; Miyake, K. Analysis of vibration damping properties of hybrid composite with flexible matrix resin. J. Soc. Mater. Sci. Jpn. 1996, 45, 160-165. [CrossRef]

9. Perez, J.C.L.; Kwok, C.Y.; Senetakis, K. Effect of rubber content on the unstable behaviour of sand-rubber mixtures under static loading: a micro-mechanical study. Géotechnique 2017, 68, 1-14. [CrossRef]

10. Liu, Z.; Zhang, Y. Enhanced mechanical and thermal properties of SBR composites by introducing graphene oxide nanosheets decorated with silica particles. Compos. Part A Appl. Sci. Manuf. 2017, 102, 236-242. [CrossRef]

11. Berki, P.; Göbl, R.; Karger-Kocsis, J. Structure and properties of styrene-butadiene rubber (SBR) with pyrolytic and industrial carbon black. Polym. Test. 2017, 61, 404-415. [CrossRef]

12. Xu, H.; Han, J.; Fang, L.; Shen, F.; Wu, C. Effect of grafted carbon black on properties of vulcanized natural rubber. Polym. Bull. 2007, 58, 951-962. [CrossRef]

13. Nayak, S.; Chaki, T.K. Effect of hybrid fillers on the nonlinear viscoelasticity of rubber composites and nanocomposites. In Non-Linear Viscoelasticity of Rubber Composites and Nanocomposites; Springer International Publishing: Cham, Switzerland, 2014; pp. 135-160.

14. Omnès, B.; Thuillier, S.; Pilvin, P.; Grohens, Y.; Gillet, S. Effective properties of carbon black filled natural rubber: Experiments and modeling. Compos. A Appl. Sci. Manuf. 2008, 39, 1141-1149. [CrossRef]

15. Pan, X.-D.; Kelley, E.D. Enhanced apparent payne effect in a gum vulcanizate at low temperature approaching glass transition. Polym. Eng. Sci. 2003, 43, 1512-1521. [CrossRef]

16. Mandal, U.K.; Tripathy, D.K.; De, S.K. Effect of carbon-black fillers on dynamic-mechanical properties of ionic elastomer based on carboxylated nitrile rubber. Plast. Rubber Compos. Process. Appl. 1995, 24, 19-25.

17. Lénárt, J. Contactless vibration measurement using linear CCD sensor. In Proceedings of the 13th International Carpathian Control Conference (ICCC), High Tatras, Slovakia, 28-31 May 2012; pp. 426-429.

18. Cao, Y.; Rong, X.L.; Shao, S.J.; He, K.P. Present situation and prospects of vibration sensors. In Proceedings of the 2012 International Conference on Computer Distributed Control and Intelligent Environmental Monitoring, Zhangiiajie, Hunan, China, 5-6 March 2012; pp. 515-518.

19. Volpe, R.; Ivlev, R. A survey and experimental evaluation of proximity sensors for space robotics. In Proceedings of the 1994 IEEE International Conference on Robotics and Automation, San Diego, CA, USA, 8-13 May 1994; pp. 3466-3473. 
20. Chaurasiya, H. Recent trends of measurement and development of vibration sensors. Int. J. Com. Sci 2012, 9, $1-6$.

21. Botelho, E.C.; Campos, A.N.; de Barros, E.; Pardini, L.C.; Rezende, M.C. Damping behaviour of continuous fiber/metal composite materials by the free vibration method. Compos. B Eng. 2005, 37, 255-263. [CrossRef]

22. Rao, S.S. Mechanical Vibrations, 5th ed.; Pearson Education: Upper Saddle River, NJ, USA, 2011; Chapter 1.

23. Lapcik, L.; Vasina, M.; Lapcikova, B.; Valenta, T. Study of bread staling by means of vibro-acoustic, tensile and thermal analysis techniques. J. Food Eng. 2016, 178, 31-38. [CrossRef]

24. B\&K Sound and Vibration Measurenet. Available online: https://www.bksv.com/en/products/transducers/ vibration/Vibration-transducers/accelerometers/4393 (accessed on 12 May 2020).

25. Litvinov, V.M.; Steeman, P.A.M. EPDM-carbon black interactions and the reinforcement mechanisms, as studied by low-resolution ${ }^{1}$ H NMR. Macromolecules 1999, 32, 8476-8490. [CrossRef]

26. Heinrich, G.; Vilgis, T.A. Contribution of entanglements to the mechanical properties of carbon black-filled polymer networks. Macromolecules 1993, 26, 1109-1119. [CrossRef]

27. Li, Z.H. Effects of carbon blacks with various structures on vulcanization and reinforcement of filled ethylene-propylene-diene rubber. Express Polym. Lett. 2008, 2, 695-704. [CrossRef]

28. Li, Q.; Ma, Y.; Wu, C.; Qian, S. Effect of carbon black nature on vulcanization and mechanical properties of rubber. J. Macromol. Sci. B 2008, 47, 837-846. [CrossRef]

29. Li, Z.; Zhang, J.; Chen, S. Effect of carbon blacks with various structures on electrical properties of filled ethylene-propylene-diene rubber. J. Electrost. 2009, 67, 73-75. [CrossRef]

30. Edwards, D.C. Polymer-filler interactions in rubber reinforcement. J. Mater. Sci. 1990, 25, 4175-4185. [CrossRef]

31. Lion, A.; Kardelky, C. The payne effect in finite viscoelasticity. Int. J. Plast. 2004, 20, 1313-1345. [CrossRef]

32. Markovic, G.; Marinovic-Cincovic, M.; Jovanovic, V.; Samarzija-Jovanovic, S.; Budinski-Simendic, J. Modeling of nonlinear viscoelastic behavior of filled rubbers. In Non-Linear Viscoelasticity of Rubber Composites and Nanocomposites; Springer International Publishing: Cham, Switzerland, 2014; pp. 193-271.

33. Drozdov, A.; Dorfmann, A. The payne effect for particle-reinforced elastomers. Polym. Eng. Sci. 2002, 42, 591-604. [CrossRef]

34. Wang, J.; Hamed, G.R.; Umetsu, K.; Roland, C. The payne effect in double network elastomers. Rubber Chem. Technol. 2005, 78, 76-83. [CrossRef]

35. Bezerra, F.D.O.; Nunes, R.C.R.; Gomes, A.S.; Oliveira, M.G.; Ito, E.N. Payne effect in NBR nanocomposites with organofilic montmorillonite. Polimeros 2013, 23, 223-228.

36. Fukahori, Y. New progress in the theory and model of carbon black reinforcement of elastomers. J. Appl. Polym. Sci. 2004, 95, 60-67. [CrossRef]

37. Júnior, J.H.A.; Júnior, H.L.O.; Amico, S.C.; Amado, F.D.R. Study of hybrid intralaminate curaua/glass composites. Mater. Des. 2012, 42, 111-117. [CrossRef]

38. Rajoria, H.; Jalili, N. Passive vibration damping enhancement using carbon nanotube-epoxy reinforced composites. Compos. Sci. Technol. 2005, 65, 2079-2093. [CrossRef]

(C) 2020 by the authors. Licensee MDPI, Basel, Switzerland. This article is an open access article distributed under the terms and conditions of the Creative Commons Attribution (CC BY) license (http://creativecommons.org/licenses/by/4.0/). 